\title{
A formalização da percepção da vogal baixa nasalizada do espanhol à luz do modelo BiPhon: estudo comparativo de fragmentos das gramáticas de falantes nativos e de brasileiros adquirindo o Espanhol como língua estrangeira
}

\section{Formalization of the perception of the nasalized low vowel in Spanish in the light of the BiPhon model: a comparative study of grammar fragments of Spanish native speakers and Brazilian students learning Spanish as a foreign language}

Luciene Bassols Brisolara

Universidade Federal do Rio Grande (FURG), Rio Grande, Rio Grande do Sul / Brasil lucienebrisolara@furg.br

http://orcid.org/0000-0001-7248-6765

Carmen Lúcia Barreto Matzenauer

Universidade Federal de Pelotas (UFPel), Pelotas, Rio Grande do Sul / Brasil

carmen.matzenauer@gmail.com

http://orcid.org/0000-0003-4505-7521

Roberta Quintanilha Azevedo

Instituto Federal Sul-Riograndense (IFSul), Pelotas, Rio Grande do Sul / Brasil betanilha@gmail.com

http://orcid.org/0000-0001-6076-9768

Resumo: Uma perspectiva formal está no foco deste artigo que visa discutir e representar a percepção da nasalização da vogal /a/ em determinados contextos nasais, fenômeno de alofonia no espanhol, que pode ser fonológico ou alofônico no português. O suporte empírico está em dados de 9 nativos da língua, de Montevidéu, e de 15 brasileiros aprendizes de espanhol como língua estrangeira. Os dados de percepção, aqui aproveitados dos estudos de Brisolara e Matzenauer (2018a, 2018b), 
foram obtidos em Teste de Identificação, elaborado no software TP (RAUBER et al., 2012). A menor acuidade dos uruguaios na identificação de vogais nasalizadas, em comparação aos brasileiros, atribuída ao caráter estritamente alofônico do fenômeno no espanhol, foi captada e formalizada no Modelo Bidirecional de Processamento e de Gramática - BiPhon (BOERSMA, 2006, 2007; BOERSMA; HAMANN, 2009), que integra a Teoria da Otimidade Estocástica. Como a percepção, segundo o BiPhon, tem o papel de mapear a representação fonética contínua para uma estrutura de superfície fonológica discreta, o fenômeno da percepção da nasalização da vogal /a/ no espanhol foi formalizado de modo que representou, pela interação entre Restrições de Pista e de Estrutura, a diferença da gramática dos brasileiros enquanto aprendizes de espanhol em relação à gramática dos uruguaios: o peso das Restrições de Estrutura * $\mathrm{V}_{\mathrm{ORAL}} \mathrm{N}$ e *Vnasal foi decisivo na especificação de cada uma das duas gramáticas, sendo que a proximidade dos valores centrais das Restrições de Estrutura e de Pista representou a presença de variação nos dados de percepção tanto de uruguaios, como de brasileiros.

Palavras-chave: percepção; nasalização vocálica no espanhol; modelo BiPhon.

Abstract: A formal perspective is the focus of this paper, which aims to discuss and represent the perception of nasalization of vowel /a/ in certain nasal contexts, a phenomenon of allophony in Spanish, which can be either phonological or allophonic in Portuguese. Empirical support is based on data from 9 native speakers from Montevideo, Uruguay, and 15 Brazilian learners of Spanish as a second language. Perception data, taken from studies carried out by Brisolara and Matzenauer (2018a, 2018b), were obtained by an Identification Test, which was run by the TP software program (RAUBER et al., 2012). The fact that the Uruguayan have lower accuracy than the Brazilian to identify nasalized vowels is attributed to the strict allophonic nature of the phenomenon in Spanish. It was captured and formalized by the Bidirectional Processing and Grammar Model - BiPhon (BOERSMA, 2006, 2007; BOERSMA; HAMANN, 2009), which integrates the Stochastic Optimality Theory. Since perception, according to BiPhon, has the role of mapping continuous phonetic representation to a discrete phonological surface structure, the phenomenon related to the perception of nasalization of the vowel /a/ in Spanish was formalized in a way that represented, through the interaction between Cue Constraints and Structural Constraints, the difference between grammars of Brazilian Spanish learners and of Uruguayans: the weight of the ${ }^{*} \mathrm{~V}_{\mathrm{ORAL}} \mathrm{N}$ and $*$ Vnasal Structural Constraints was decisive in specifying both grammars, and the proximity of the central values of the Structural and Cue Constraints represented the presence of variation in the perception data of the Uruguayan and the Brazilian.

Keywords: perception; vowel nasalization in Spanish; BiPhon model. 


\section{Introdução}

O foco deste artigo está na percepção da nasalidade vocálica do espanhol, fenômeno que nesta língua é alofônico e que, no português, pode ser fonológico (ex.: grupo $\mathrm{VN}$ - manta) ou alofônico (ex.: grupo V.N - cama), sob uma perspectiva formal. O recorte do tema foi teoricamente delineado a partir do reconhecimento de que há divergência, em abordagens fonológicas e fonéticas de fatos linguísticos, na concepção da natureza das representações atinentes à produção, sendo raras as discussões relativas ao locus da percepção na gramática das línguas. É nesta lacuna que o trabalho se insere, chegando à discussão do ponto em que o conhecimento fonológico guia o processo de percepção da fala, com o suporte teórico de um modelo de processamento e de gramática.

Para tanto, partindo-se do entendimento inovador de que a percepção tem natureza fonológica, a diferença do status da nasalidade vocálica nesses dois sistemas linguísticos levou à formulação de duas questões a serem respondidas: (a) como se caracterizam os comportamentos de falantes nativos do português do Brasil (PB), no processo de aquisição do espanhol como língua estrangeira (LE), e dos uruguaios, falantes nativos desta língua, com referência à percepção de vogais nasalizadas presentes no espanhol?; (b) como se representa a possível diferença entre a percepção da nasalidade vocálica por falantes nativos de português e falantes nativos de espanhol em um modelo formal, que integre percepção e gramática fonológica?

A resposta à questão norteadora "a" foi proposta na busca de evidências não apenas sobre o comportamento dos nativos de espanhol e falantes de português adquirindo espanhol e suas possíveis dificuldades na percepção da vogal /a/ nasalizada do espanhol, mas também na procura de tendências universais no comportamento dos participantes da pesquisa. Tais resultados foram capazes de oferecer a base do processo de proposição de restrições na construção da resposta à questão "b", em um modelo que pressupõe a existência de uma Gramática Universal e do mapeamento entre as representações do input e do output linguístico por meio de restrições.

Assim, foi possível a reflexão acerca de fatos teóricos e empíricos relevantes, como: (a) a relação entre percepção e gramática; (b) a retomada do debate sobre relações importantes para o entendimento da natureza dos fenômenos linguísticos, como parte do conjunto de 
pesquisas voltadas para a teoria fonológica; (c) a inter-relação entre os níveis de representação da língua e (d) a forma como se podem captar aspectos gradientes da língua, verificando-se que a interação entre níveis representacionais tem participação na teoria linguística.

$\mathrm{O}$ estudo, centrado na vogal /a/ do espanhol, examinou dados obtidos a partir de um Teste de Identificação, proposto por Brisolara e Matzenauer (2018a, 2018b), elaborado com o uso do software TP (RAUBER et al., 2012), sendo que a análise e a formalização dos resultados encontraram suporte no Modelo Bidirecional de Processamento e de Gramática - BiPhon (BOERSMA, 2006, 2007, 2010, 2011; BOERSMA; PATER, 2008; BOERSMA; HAMANN, 2009). Segue-se o entendimento expresso pelos autores de que a percepção tem natureza fonológica, cumprindo o papel, formalizado no BiPhon, de fazer um mapeamento da representação fonética contínua para uma estrutura de superfície fonológica discreta.

O objetivo do estudo, portanto, foi discutir e formalizar a percepção de um fenômeno de alofonia no espanhol, representado pela nasalização da vogal /a/ em determinados contextos nasais, por falantes nativos da língua e por brasileiros em processo de aquisição do espanhol como língua estrangeira, com os fundamentos do BiPhon. Destaca-se que a opção por investigar a vogal /a/ deveu-se ao fato de que o grau de nasalidade de vogais baixas é maior e, por essa razão, mais perceptível do que o de vogais não baixas (PASCA, 2003; SEARA, 2000).

Com o desenho proposto, este estudo, além de formalizar a percepção da vogal /a/ do espanhol a partir do modelo Biphon, contribuirá para a discussão sobre a importância da percepção de sons de caráter alofônico no aprendizado de espanhol como língua estrangeira, bem como sobre a necessidade do conhecimento dos sistemas fonéticofonológico de línguas próximas, o que pode auxiliar tanto professores quanto estudantes de LE na busca de estratégias para um desempenho mais adequado na língua-alvo.

Divide-se o artigo em seções, de forma a trazerem-se, de início, noções basilares para a observação da nasalidade vocálica no espanhol e no português brasileiro e para a explicitação de pressupostos do Modelo BiPhon; após, apresentam-se os procedimentos metodológicos que orientaram a investigação e, subsequentemente, mostram-se os resultados, seguidos, finalmente, da análise e da formalização propostas à luz do Modelo BiPhon. 


\section{Noções substanciais para o estudo}

Linhas gerais do comportamento da nasalidade vocálica no espanhol e no português brasileiro, bem como de pressupostos do Modelo BiPhon são aqui apresentados.

\subsection{A nasalização vocálica no espanhol e no português brasileiro}

A nasalização vocálica no espanhol apresenta caráter fonético, de acordo com Navarro Tomás (1918 [2004]) e Quilis (1999), não contrastando significado. O fenômeno ocorre em dois contextos específicos, a saber: (a) quando a vogal é precedida e seguida por consoantes nasais, independentemente de a segunda consoante estar em posição de coda (ex.: manso) ou de onset da sílaba seguinte (ex.: manera); (b) quando a vogal se encontra em início absoluto seguida de consoante nasal (ex.: antigua). ${ }^{1}$ Nos demais contextos, a vogal será produzida como oral. Para Pasca (2003) e Haro (2011), ainda que a nasalização seja verificada no espanhol, esta é praticamente imperceptível para a maioria dos falantes nativos exatamente por tratar-se de fenômeno alofônico.

No português brasileiro, por outro lado, seguindo-se Câmara Jr. (1977) e Bisol (2002), a nasalização manifesta-se de duas maneiras: a primeira é de cunho fonológico, ocorrendo a sequência vogal + nasal em contexto tautossilábico (VN), exemplo, 'manto', provocando contraste de significado em pares como 'mato' x 'manto'. Também

\footnotetext{
${ }^{1}$ Esses são os contextos de nasalização vocálica no espanhol reconhecidos pela literatura clássica (NAVARRO TOMÁS, 1918 [2004]; QUILIS, 1999) e por estudos contemporâneos, como o de Hualde e Colina (2014); por isso, foram eleitos para discussão no presente artigo. Reconhece-se, no entanto, a possibilidade de nasalização vocálica em outros contextos por simples efeito de coarticulação com segmentos nasais. Esse fato é reconhecido por Vaquero de Ramírez (2003) que, ao tratar do espanhol do Caribe, afirma que a nasalização pode ocorrer em todas as vogais de uma palavra que possua consoante nasal, como em 'San Juan', 'salíamos' e 'empezar', em que todas as vogais são nasalizadas. Destaca-se, no entanto, que, apesar de o processo de nasalidade no espanhol poder ocorrer em outros contextos que não os encontrados em Navarro Tomás ([1918]2004) e Quilis (1999), as análises dos valores acústicos, especialmente de F1 e F3, dos dados dos locutores do presente estudo, no que tange às palavras apresentadas no Quadro 1 , evidenciaram a nasalização da vogal baixa nos dois contextos apontados por Navarro Tomás ([1918] 2004) e Quilis (1999), e a não nasalização nos demais contextos.
} 
existe a nasalização de caráter fonético, em que a sequência vogal + nasal ocorre em contexto heterossilábico (V.N), exemplo, 'caneta' $e$ 'abanar', não provocando mudança de significado, manifestando-se apenas foneticamente.

\subsection{O Modelo Biphon}

O Modelo Bidirecional de Processamento e de Gramática (Modelo BiPhon) interpreta e formaliza o processamento linguístico por meio da previsão de níveis de representação que integram os processos de Compreensão e de Produção no uso da língua pelos falantes. Constitui-se também em um Modelo de Gramática por modelar a articulação entre os níveis representacionais através de restrições, que mapeiam as formas linguísticas nos moldes da Teoria da Otimidade Estocástica.

Abordagens como a Teoria da Otimidade Estocástica e o Modelo BiPhon propõem que as formas de superfície observadas surgem como um output que é ótimo porque satisfaz mais harmonicamente uma hierarquia de restrições. Tal perspectiva, presente nestes modelos teóricos, difere de análises fonológicas tradicionais que utilizam regras para a representação dos fenômenos nas línguas, mapeando a representação subjacente (input) na realização de superfície (output). ${ }^{2}$ Há relevância em observar-se que, nos modelos gerativos diferentes do BiPhon, a relação entre input e output implica dois níveis de representação.

Entretanto, o BiPhon vai além, pois considera três níveis de representação: a [Forma Fonética], a /Forma Fonológica de Superfície/ e a |Forma Subjacente|. Sendo fonética a natureza do primeiro nível e fonológica a natureza dos dois outros, o modelo manifesta o entendimento da relação entre Fonética e Fonologia e expressa a passagem do continuum fonético para o discreto fonológico no movimento que se opera no uso e no funcionamento da língua. Pelo fato de o modelo ser bidirecional,

\footnotetext{
${ }^{2}$ Nos modelos teóricos com base em regras, o mapeamento entre o input e o output ocorre por meio da aplicação de regras, enquanto nos modelos teóricos com base em restrições, como a Teoria da Otimidade (OT), o mapeamento entre o input e output ocorre por meio da satisfação de restrições, que obedecem a uma hierarquia que é específica de cada língua. A Teoria da Otimidade Estocástica tem duas particularidades primordiais que a diferem da OT clássica: (a) atribui valores às restrições para o estabelecimento da hierarquia, (b) está atrelada a um algoritmo de aprendizagem: o Algoritmo de Aprendizagem Gradual (GLA - Gradual Learning Algorithm).
} 
esses três níveis integram dois módulos: o Módulo da Compreensão e o Módulo da Produção linguística.

$\mathrm{Na}$ Figura 1, estão formalizados os níveis de representação e os dois módulos. A característica de ser um Modelo de Processamento é representada pelas flechas, enquanto a característica de ser um Modelo de Gramática é representada pelas restrições (Restrições de Pista (Cue Constraints); Restrições de Estrutura (Structural Constraints); Restrições de Fidelidade (Faithfulness Constraints)).

FIGURA 1 - Modelo Bidirecional de Processamento e de Gramática (BiPhon Model)
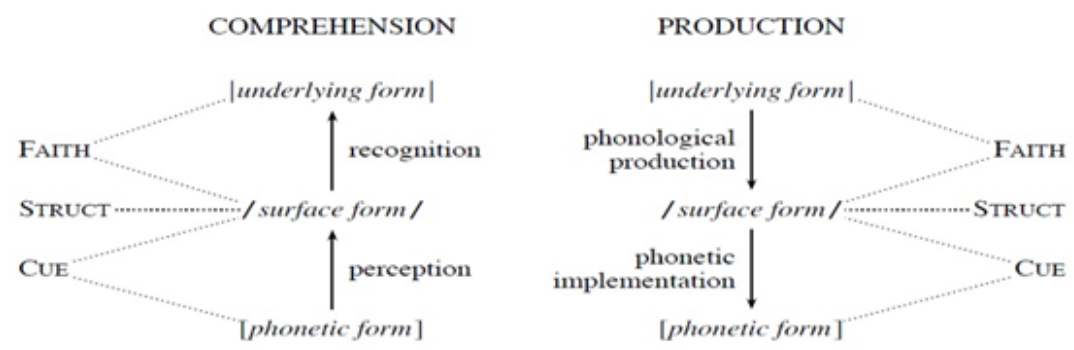

Fonte: Boersma; Hamann (2009, p. 1)

O Modelo BiPhon é um modelo de processamento, porque descreve o uso da língua na produção e na compreensão, e um modelo de gramática, porque representa e explica o funcionamento da língua pela organização de restrições em uma hierarquia, ${ }^{3}$ assumindo a existência de níveis contínuos e discretos na teorização linguística.

Dessa forma, é capaz de lidar com a gradualidade na criação de categorias e de lidar com a dispersão auditiva, ${ }^{4}$ no sentido de que explicita que existem pistas acústicas distintivas que são codificadas como contrastes fonológicos, as quais podem ser perceptualmente mais

\footnotetext{
${ }^{3}$ Adotar-se-á o pressuposto da Teoria da Otimidade, segundo o qual o conhecimento é representado como uma gramática que consiste em um ranking de restrições (BiPhon - OT), conforme começou a ser explicitado na Nota 2.

${ }^{4}$ O termo dispersão recupera a Teoria da Dispersão de Lindblom (1972) e refere a separação dos sons no espectro sonoro, que resulta em uma maximização da distinção entre os contrastes dos sons, com a ideia de que há uma preferência por contrastes distintos, hipotetizada a partir de uma preferência por minimizar a confusão perceptual para recuperar o que o falante está dizendo.
} 
salientes do que diferenças entre pistas não distintivas para falantes de determinado sistema linguístico.

Nesse sentido, o modelo é capaz de captar e de formalizar o comportamento linguístico do falante, do ouvinte e do aprendiz. ${ }^{5}$ Os níveis de representação e a hierarquização das restrições têm de ser estabelecidos na construção das formas tanto de natureza fonética, como fonológica. ${ }^{6}$

As restrições são de três tipos: Restrições de Fidelidade, Restrições de Estrutura e Restrições de Pista. Destaca-se que as Restrições de Pista têm caráter puramente fonético: na percepção, que ocorre no Módulo da Compreensão, mapeiam a [Forma Fonética] ([Forma Auditiva]) em /Forma Fonológica de Superfície/; na implementação fonética, que ocorre no Módulo da Produção, mapeiam a /Forma Fonológica de Superfície/ em [Forma Fonética] ([Forma Articulatória]). O entendimento de Boersma (2007) de que a percepção também é condicionada pelas Restrições de Estrutura, na sua interação com as Restrições de Pista, leva ao reconhecimento da natureza fonológica da percepção linguística.

Ressalta-se que a atribuição de status fonológico à percepção é crucial para o estudo relatado neste artigo, estando subjacente à questão inicialmente proposta: é plausível propor-se que poderá haver diferença na percepção da vogal /a/ nasalizada no espanhol, considerando-se falantes nativos desta língua e falantes nativos de $\mathrm{PB}$, tendo em vista $\mathrm{o}$ tratamento diverso da nasalidade vocálica nos dois sistemas linguísticos, se houver o entendimento de que a percepção tem caráter fonológico.

Destaca-se que esse foco do artigo exigiu que a análise ficasse centrada, no BiPhon, no Módulo da Compreensão e particularmente em dois níveis representacionais: na [Forma Fonética] ([Forma Auditiva]) e na/Forma Fonológica de Superfície/ e no mapeamento do primeiro para o segundo nível por meio da interação entre Restrições de Pista e Restrições de Estrutura (veja-se FIGURA 1). Salienta-se ainda que, em virtude de

\footnotetext{
${ }^{5}$ Entende-se que o modelo, embora tenha sido primeiramente proposto para tratar da L1, também é pertinente para explicar o processo de aquisição de uma LE; esse entendimento decorre não apenas das propriedades que definem o BiPhon, mas também do fato de estar no substrato da proposta de Escudero (2005), cujo foco está na aquisição de L2. ${ }^{6} \mathrm{O}$ Modelo BiPhon não está limitado aos níveis de representações apresentados. Boersma; Hamann (2009) assumem que a Figura 1 seria a representação mais resumida do modelo, no entanto, suficiente, para uma análise fonológica.
} 
a fonologia do espanhol não conter vogais nasais, o fato de usar-se, nos tableaux mostrados na Seção denominada 'Simulações de Gramática', a forma /ã/ não representa a categorização, pelos informantes, de uma vogal nasal fonológica; na verdade, representa apenas a percepção, pelos informantes, de um movimento, de caráter fonético-fonológico, de natureza variável, que o sistema do espanhol contém.

Salienta-se ainda que, operando nos moldes da OT Estocástica, ${ }^{7}$ o BiPhon passa a ter a ele vinculado um algoritmo de aprendizagem: o Algoritmo de Aprendizagem Gradual (GLA), proposto por Boersma; Hayes (2001). O objetivo do GLA é guiar o aprendiz à hierarquia de restrições específica da sua língua, ou seja, é chegar à gramática da língua-alvo pela atribuição de um valor, a cada restrição, que a localize no ranqueamento correspondente àquela língua. ${ }^{8}$

O uso dos pressupostos da OT Estocástica para a explicação e a formalização de fenômenos de uma gramática, seja de percepção (foco do presente artigo), seja de produção linguística, impõe a vantagem de reconhecer e formalizar a ocorrência de fatos em variação, já que inclui a previsão de sobreposição de restrições, desde que seus "valores centrais" mostrem distância inferior a 10 pontos, conforme representação na Figura 2.

FIGURA 2 - Sobreposição de restrições em um ranking

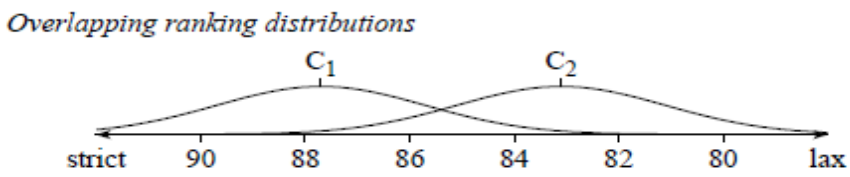

Fonte: Boersma; Hayes (2001, p.5)

Essa sobreposição de restrições evidencia a possibilidade de as Restrições $1\left(\mathrm{C}_{1}\right)$ e $2\left(\mathrm{C}_{2}\right)$ poderem ter sua posição invertida na hierarquia,

\footnotetext{
${ }^{7}$ A OT Estocástica está incluída no BiPhon, ou seja, faz parte do Modelo, para que ele possa cumprir a sua função como "modelo de gramática": é pela aplicação da OT Estocástica que as restrições relacionadas aos três níveis de representação do BiPhon são hierarquizadas, a fim de que seja apontado o output ótimo.

${ }^{8} \mathrm{Na}$ OT Estocástica, as restrições recebem valores numéricos que são responsáveis pela posição que ocupam na hierarquia que representa a gramática da língua - veja-se Nota 2.
} 
o que acarretaria a escolha de um diferente "output ótimo", expressando a ocorrência de variação linguística. Nesse sentido, cada restrição recebe 2 pesos numéricos: (a) ranking value (= média ou centro de uma faixa de valores) e (b) disharmony (= ponto de seleção dentro da mesma faixa de valores). ${ }^{9}$ O peso central é um valor fixo em um certo estágio de aprendizagem; já o ponto de seleção varia a cada momento de produção linguística, o que garante duas predições relevantes: (1) prever, para o mesmo estágio desenvolvimental no curso da aprendizagem, outputs variáveis e (2) prever quais destes outputs são mais frequentes. $\mathrm{O}$ output que viola a restrição com maior valor/peso central acontecerá menos vezes como ótimo, já que esta restrição terá maior probabilidade de assumir posições mais altas na hierarquia.

Essa funcionalidade do algoritmo é implementada no sistema PRAAT $^{10}$ (BOERSMA; WEENINK, 2013). A partir de dois scripts - 1 script com informações sobre quais são os candidatos a output e os percentuais de ocorrência de cada candidato no corpus estudado e outro script com as restrições pensadas pelo pesquisador para a formalização dos dados -, o software vai percorrer quatro passos, começando de um estágio inicial até chegar no output ótimo. Os scripts são textos com linguagens de programação que consistem de menus de comandos e, quando executados, os comandos são acionados e a gramática é aprendida pelo sistema. Cada simulação de uma mesma gramática representa um momento de produção linguística, o que quer dizer que cada rodada do sistema representa um momento de produção linguística: esse modus operandi é que permite a verificação de outputs variáveis.

Tal pressuposto da OT Estocástica é relevante para a análise proposta no estudo da percepção da nasalidade vocálica no espanhol, tema deste artigo, já que os dados refletem resultados de natureza variável.

\footnotetext{
${ }^{9}$ No exemplo expresso na Figura 2, o ranking value (valor central) da $\mathrm{C}_{1}$ é 88 e o ranking value da $\mathrm{C}_{2}$ é 82 - por sua diferença ser inferior a 10 pontos, pode ocorrer de essas restrições terem sua posição hierárquica invertida: se, em uma rodada do Programa, o valor de disharmony (ponto de seleção) de $\mathrm{C}_{2}$ for 86 e o valor de disharmony de $\mathrm{C}_{1}$ for 84 , a restrição $\mathrm{C}_{2}$ passará a dominar $\mathrm{C}_{1}$. Então, a forma de output ótimo será diferente daquela escolhida quando a restrição $\mathrm{C}_{1}$ dominava $\mathrm{C}_{2}-$ esse movimento entre as restrições explica as formas em variação na língua, de acordo com a OT Estocástica. ${ }^{10}$ Maiores detalhes sobre a operacionalização do algoritmo podem ser obtidos em Boersma e Hayes (2001) e Alves (2017).
} 


\section{Metodologia}

Apresenta-se a seguir o delineamento da pesquisa, com a explicitação de dados referentes aos informantes e aos procedimentos metodológicos adotados.

\subsection{Informantes}

O corpus usado para a presente pesquisa foi coletado para um estudo sobre percepção ${ }^{11}$ (BRISOLARA; MATZENAUER, 2018a, $2018 \mathrm{~b})$ que contou com a participação de nove falantes nativos do espanhol, residentes em Montevidéu e Maldonado ${ }^{12}$ (Uruguai), sendo seis mulheres e três homens, com idade entre 18 e 23 anos, todos estudantes da Facultad de Comunicación e Información de la Universidad de la República. Além dos nativos de espanhol, também participaram do estudo 15 brasileiros aprendizes de espanhol, estudantes do primeiro semestre do Curso de Letras, habilitação Português-Espanhol, da Universidade Federal do Rio Grande, sendo 10 mulheres e cinco homens, com idade entre 18 e 49 anos, todos residentes na cidade do Rio Grande e nascidos no Rio Grande do Sul, pertencentes a uma mesma região dialetal. ${ }^{13}$

\subsection{Procedimento}

Com base em instrumento elaborado por Brisolara e Matzenauer (2018a; 2018b), constituído por quatro testes de percepção, sendo três de discriminação e um de identificação, analisou-se aqui exclusivamente o

\footnotetext{
${ }^{11}$ A coleta de dados foi realizada para o estudo de pós-doutoramento de Luciene Bassols Brisolara, supervisionado por Carmen Lúcia Barreto Matzenauer, cujos resultados foram publicados em Brisolara e Matzenauer (2018a, 2018b). Posteriormente, os mesmos dados foram utilizados para a elaboração do presente trabalho, a fim de formalizar no Modelo Biphon os resultados encontrados nos estudos aqui mencionados.

${ }^{12}$ Inicialmente o estudo seria aplicado somente a sujeitos de Montevidéu, no entanto, devido à dificuldade de encontrar universitários que não falassem português e que tampouco tivessem estudado o idioma formalmente, optou-se por incluir estudantes da mesma universidade que viviam em Maldonado, que fica a aproximadamente 120 $\mathrm{km}$ de Montevidéu.

${ }^{13}$ Este estudo foi aprovado pelo Comitê de Ética da Universidade Católica de Pelotas - Processo $\mathrm{n}^{\circ}$ 68282417.3.0000.5339 e todos os participantes assinaram um Termo de Consentimento Livre e Esclarecido.
} 
Teste de Identificação por entender-se, seguindo-se Boersma e Hamann (2009), que perceber é identificar; os resultados deste teste oferecem as condições para formalizar-se o processo de percepção de alofonia do espanhol, representado pela nasalização da vogal /a/ nos contextos descritos na Seção 2.1, no modelo BiPhon (BOERSMA; HAMANN, 2009).

Destaca-se que, para o Teste de Identificação, foram selecionadas, como estímulos, 22 palavras com a vogal /a/ precedida e/ou seguida de consoante nasal, todas dissilábicas ou trissilábicas. Em 10 das palavras havia contexto de nasalização vocálica no espanhol e, em 12, não, conforme pode ser visualizado no Quadro 1.

QUADRO 1 - Palavras que integraram o Teste de Identificação

\begin{tabular}{|c|c|c|c|}
\hline \multicolumn{2}{|c|}{ Vogal Tônica } & \multicolumn{2}{c|}{ Vogal Átona } \\
\hline Nasal & Oral & Nasal & Oral \\
\hline manto & lámpara & manera & bandido \\
\hline manso & urbano & antigua & panfleto \\
\hline máncer & pánico & mandato & sanfona \\
\hline manfla & danto & mangrullo & bandujo \\
\hline almante & fango & ampuloso & candado \\
\hline & alacrán & & gambocho \\
\hline
\end{tabular}

Fonte: Brisolara e Matzenauer (2018b, p. 21)

Conforme o Quadro 1, as palavras foram divididas, dependendo da caracterização da vogal /a/, em tônicas e átonas, orais e nasais. Além disso, o instrumento elaborado por Brisolara e Matzenauer (2018a, 2018b) também classificou as palavras em cognatas e não cognatas, a fim de verificar-se se haveria diferença de acertos considerando a similaridade ou não das palavras com o português. No entanto, o resultado encontrado pelas autoras em ambos os estudos não foi significativo. Assim, no presente estudo, a similaridade ou diferença das palavras do espanhol com relação ao português não será discutida.

As palavras tomadas como estímulos no Teste de Identificação foram gravadas por dois locutores, um homem argentino, residente no Brasil, e uma mulher brasileira, que viveu por mais de uma década na Argentina, tendo realizado seus estudos primários e secundários no país 
estrangeiro. Os locutores tinham cerca de 40 anos e eram professores universitários de espanhol em um curso de formação de professores de línguas. ${ }^{14}$ Cada estímulo foi gravado duas vezes por cada locutor.

Os dados linguísticos dos locutores foram gravados em uma cabine acústica com o uso de um microfone com taxa de amostragem de $44.100 \mathrm{~Hz}$, 16bits. Para garantir a produção da nasalização vocálica nos contextos previstos pela literatura (veja-se Seção 2.1), foram criadas duas frases-veículos para serem lidas pelos locutores ${ }^{15}$ - 'Diga X otra vez' e ' $X$ es una palabra del español'; ${ }^{16}$ no espaço de $\mathrm{X}$ eram inseridas as palavras do Quadro 1. Cumpre ressaltar que não houve coleta de dados neste estudo. Assim, as palavras gravadas pelos locutores em Brisolara e Matzenauer (2018a, 2018b), selecionadas para a aplicação do teste de percepção com a vogal foco /a/, foram analisadas acusticamente para confirmar-se se cada vogal estava sendo produzida como oral ou nasalizada, para que se pudesse afirmar, na formalização do presente artigo, qual o input se estaria considerando para a percepção dos informantes.

Para a análise acústica foram observados os mesmos parâmetros de Brisolara, Matzenauer e Seara (2019), ${ }^{17}$ já que a comparação destes

${ }^{14}$ Os dois locutores foram escolhidos por sua alta proficiência em ambas as línguas, sendo que são professores universitários de espanhol, com formação superior em cursos de Licenciatura Português-Espanhol, além de terem o nível superior no Diploma de Espanhol como Língua Estrangeira. Mesmo residindo no Brasil, os dois locutores usam predominantemente o espanhol nos contextos familiar e universitário.

${ }^{15}$ Os locutores realizaram a leitura e, consequentemente, a gravação de palavras em frases-veículo, não configurando fala espontânea. As frases-veículo cumpriram a função de evitar o efeito de leitura de lista de palavras isoladas, garantindo o efeito prosódico de frase e também assegurando a presença dos contextos que são objeto de análise.

${ }^{16}$ No que tange às frases-veículo, é importante destacar que, considerando os contextos de nasalização apontados em Navarro Tomás (2004[1918]) e Quilis (1999), a frase "Diga...otra vez" não garantiria a nasalização da vogal em início absoluto seguido de nasal, porque sempre haveria um contexto precedente; por essa razão, foi utilizada a frase-veículo “... es una palabra del español”. Portanto, palavras como "manto, lámpara, manera, bandido" foram gravadas usando-se a frase "Diga...otra vez" e palavras como "ampuloso, antigua" foram gravadas usando-se a frase ".. es una palabra del español". ${ }^{17}$ Em Brisolara, Matzenauer e Seara (2019), foram extraídas médias de F1, F2, F3 e duração da forma fonética da vogal /a/, em que o segmento não tem contato com consoante nasal, e da vogal /aN/, em que a vogal baixa é seguida por uma nasal, através de um script elaborado por Fernando Santana Pacheco, que coletou cinco pontos equidistantes do som-alvo, ou seja, ponto 1 (início), pontos 2,3 e 4 (meio), ponto 5 
resultados dos locutores foi feita com os valores apresentados naquele trabalho.

Tais frases foram apresentadas aos locutores em slides no Power Point, havendo quatro segundos de intervalo entre cada frase. Após a gravação das frases-veículo, procedeu-se à sua segmentação no Software PRAAT (BOERSMA; WEENINK, 2013), e cada estímulo foi salvo em arquivo com o formato .wav. ${ }^{18}$ Esses estímulos (palavras com a vogal /a/) foram utilizados para a construção do Teste de Identificação, que foi criado no Software TP ${ }^{19}$ (RAUBER et al., 2012), conforme já foi referido. Com o uso do site random, ${ }^{20}$ os estímulos foram aleatorizados automaticamente, havendo alternância entre a voz do locutor masculino e do feminino; selecionaram-se 11 estímulos produzidos pelo homem e 11 pela mulher ${ }^{21}$ e não foram usados distratores. As gravações dos

(fim do segmento), sendo selecionado o ponto 3 para a pesquisa, em virtude de ser a parte mais estável do segmento.

${ }^{18}$ Após a gravação das frases-veículo, as palavras-alvo foram segmentadas das frases no software PRAAT e inseridas no software TP. Durante a aplicação do teste, diante do computador, os informantes acessavam telas em que lhes era perguntado se a vogal "a" no estímulo escutado era produzida como oral ou nasal. A resposta era dada ao clicar em um ou em outro botão: oral ou nasal. Ainda que, no caso dos falantes nativos de espanhol, a nasalidade seja apenas alofônica, e que muitas vezes os falantes não percebam quando nasalizam, a pergunta é pertinente, já que pode evidenciar que os falantes nativos de espanhol não discriminam nasal e oral em sua língua, embora muitas vezes produzam diferenças fonéticas, como evidenciado em Brisolara, Matzenauer e Seara (2019).

${ }^{19} \mathrm{O}$ software TP, aplicativo gratuito criado por Rauber et al. (2012), a fim de auxiliar pesquisadores na criação de testes de percepção da fala, foi usado no estudo porque, além de não exigir conhecimento de programação, fornece resultado dos testes automaticamente após a sua aplicação. O software permite que sejam inseridos vários recursos, como imagens e áudios, para a sua elaboração. O Teste de Identificação proposto no software TP, para o estudo aqui exposto, foi apresentado aos informantes em um computador - a cada tela, os participantes liam a mesma frase no TP, ou seja, "¿La vocal a delante de nasal se pronuncia como...?" Após a leitura da frase, ouviam uma palavra, por exemplo, "manto" e deviam decidir se a vogal em questão era percebida como "oral" ou "nasal" e clicar na alternativa escolhida. Os participantes escutavam uma palavra por vez e, após escolherem a alternativa que julgassem mais adequada, passavam a escutar o próximo estímulo.

${ }^{20}$ Para ter acesso ao site, consultar https://www.random.org/lists/.

${ }^{21}$ Ambos os locutores gravaram duas vezes cada estímulo, totalizando 88 produções; no entanto, para a elaboração do teste de percepção, foram escolhidos 11 estímulos 
locutores serviram, portanto, como input para o Teste de Identificação que foi aplicado tanto a brasileiros como a uruguaios.

Os estudantes brasileiros realizaram o teste no Laboratório de Informática, do Instituto de Letras e Artes, da Universidade Federal do Rio Grande, Rio Grande do Sul, Brasil, e os estudantes uruguaios, em um laboratório de gravação da Facultad de Comunicación e Información de la Universidad de la República, Montevidéu, Uruguai. O teste foi aplicado a todos os estudantes brasileiros no mesmo dia, assim como foi feito com os uruguaios, tendo a duração de cerca de 20 minutos, tendo sido a coleta na cidade de Rio Grande realizada em junho de 2017 e a coleta na cidade de Montevidéu, em outubro de 2017. Todos os estudantes usaram fones de ouvido e computadores individuais para a realização do teste. $\mathrm{O}$ controle de volume foi programado por técnicos em informática em ambos os países, não permitindo que os estudantes fizessem ajustes de volume. Antes de iniciar a coleta de dados, a pesquisadora responsável pela aplicação dos testes explicava o funcionamento do software e fazia um pequeno treinamento com os estudantes com outros estímulos que não os do teste. Os alunos escutavam um estímulo de cada vez, tendo a possibilidade de ouvir duas vezes o mesmo estímulo, e precisavam optar por duas alternativas de resposta, ou seja, 'oral' ou 'nasal'; clicavam na opção desejada e ouviam o próximo estímulo. Através do Software TP, foram contabilizados os percentuais de acertos nos testes após a sua aplicação, dado que o programa salva as respostas, contabilizando erros e acertos, em arquivos do Excel.

\section{Resultados do Teste de Identificação}

Os Quadros 2 e 3 registram os resultados do Teste de Identificação dos brasileiros e dos uruguaios, extraídos do estudo de Brisolara e Matzenauer (2018a, 2018b). Entretanto, conforme relatado na Seção anterior, para a formalização destes dados no modelo Biphon é necessário definir os tipos de informações acústicas que os participantes do teste estão recebendo. Nesse sentido, optou-se por verificar, na produção dos

\footnotetext{
gravados pelo locutor masculino e 11 pelo feminino. No software TP, os 22 estímulos foram aleatorizados, ou seja, todos os participantes ouviram os mesmos estímulos, mas em ordens diferentes. Os 22 estímulos foram divididos em vogal tônica e átona, vogal nasal e oral, conforme apresentação no Quadro 1.
} 
locutores, apenas aquelas pistas acústicas essenciais para diferenciar um elemento vocálico como oral ou nasal.

A pista destacada foi a redução, nas vogais nasalizadas, do primeiro formante (F1), já que essa redução é considerada como proeminente nos estudos acústicos sobre nasalidade. Dessa forma, foram selecionadas e examinadas no sistema PRAAT as palavras com a vogal /a/, nas palavras listadas no Quadro 1, produzidas pelos locutores. Nos Quadros 2 e 3 estão registradas, então, as médias das frequências das vogais /a/ produzidas pelos locutores e recebidas como [input] pelos participantes da pesquisa.

Os acertos referem aqueles casos em que o participante da pesquisa ouviu a frequência mencionada como vogal nasalizada $(\sim 728 \mathrm{~Hz})$ e respondeu como "vogal nasal", bem como ouviu a frequência mencionada como vogal oral $(\sim 848 \mathrm{~Hz})$ e respondeu como "vogal oral". Os casos registrados como equívocos, em oposição, representam aquelas situações em que a frequência reduzida $(\sim 728 \mathrm{~Hz})$ é percebida como oral e a frequência da vogal oral $(\sim 848 \mathrm{~Hz})$ é percebida como uma vogal nasal.

Embora para a nasalização vocálica no espanhol não seja relevante o fato de a consoante nasal estar em contexto tautossilábico ou heterossilábico (veja-se Seção 2.1), essa distribuição foi considerada na observação dos resultados, tendo em vista a sua pertinência no português, já que nesta língua apenas é alofônica a nasalização vocálica com a consoante nasal heterossilábica. Assim, nos Quadros 2 e 3 a seguir, bem como nas simulações de Gramáticas, na Seção 6, as palavras informadas são exemplificativas dos dois tipos de contextos.

QUADRO 2 - Resultados do Teste de Identificação relativos à

Compreensão da vogal /a/ com a nasal em contexto tautossilábico

\begin{tabular}{|c|c|c|c|c|}
\hline & \multicolumn{2}{|c|}{ BRASILEIROS } & \multicolumn{2}{c|}{ URUGUAIOS } \\
\hline $\begin{array}{c}\text { VOGAL NASALIZADA } \\
(\mathrm{F} 1=\sim 728 \mathrm{~Hz})\end{array}$ & Acerto & Equívoco & Acerto & Equívoco \\
\hline $\mathbf{m}[\mathbf{a}]$ nto $\rightarrow$ m/ã $/$ nto & $46,30 \%$ & $53,70 \%$ & $36,42 \%$ & $63,58 \%$ \\
\hline $\begin{array}{c}\text { VOGAL ORAL } \\
(\mathrm{F} 1=\sim 848 \mathrm{~Hz})\end{array}$ & Acerto & Equívoco & Acerto & Equívoco \\
\hline $\mathbf{p}[\mathbf{a}] \mathbf{n f l e t o} \rightarrow \mathbf{p} / \mathbf{a} / \mathbf{n f l e t o}$ & $62,67 \%$ & $37,33 \%$ & $55,56 \%$ & $44,44 \%$ \\
\hline
\end{tabular}

Fonte: Elaboração própria 
QUADRO 3 - Resultados do Teste de Identificação relativos à

Compreensão da vogal /a/ com a nasal em contexto heterossilábico

\begin{tabular}{|c|c|c|c|c|}
\hline & \multicolumn{2}{|c|}{ BRASILEIROS } & \multicolumn{2}{c|}{ URUGUAIOS } \\
\hline $\begin{array}{c}\text { VOGAL NASALIZADA } \\
(\mathrm{F} 1=\sim 728 \mathrm{~Hz})\end{array}$ & Acerto & Equívoco & Acerto & Equívoco \\
\hline $\mathbf{m}[\tilde{a}]$ nera $\rightarrow$ m/ã $/ \mathbf{n e r a}$ & $33,33 \%$ & $66,67 \%$ & $11,11 \%$ & $88,89 \%$ \\
\hline $\begin{array}{c}\text { VOGAL ORAL } \\
(\mathrm{F} 1=\sim 848 \mathrm{~Hz})\end{array}$ & Acerto & Equívoco & Acerto & Equívoco \\
\hline $\mathbf{p}[\mathbf{a}] \mathbf{n i c o} \rightarrow \mathbf{p} / \mathbf{a} / \mathbf{n i c o}$ & $76,67 \%$ & $23,33 \%$ & $77,78 \%$ & $22,22 \%$ \\
\hline
\end{tabular}

Fonte: Elaboração própria

Pelos dados dos Quadros 2 e 3, viu-se respondida a primeira questão proposta: os estudantes brasileiros apresentaram maior sucesso do que os uruguaios na percepção das vogais nasalizadas do espanhol, bem como das vogais orais. $O$ índice de identificação é levemente superior nos dados dos uruguaios em comparação com os brasileiros apenas quando a vogal é oral em contexto heterossilábico (ex.: pánico), como pode ser observado no Quadro 3. Vê-se, no entanto, que, embora os estudantes brasileiros mostrem sucesso maior do que os uruguaios, ainda assim se equivocam em percentual acima de 50\%. Tais resultados apontam que, ainda que no português haja a nasalização fonológica e a fonética, os brasileiros, ao escutarem os estímulos em espanhol, possuem dificuldade de perceber quando a vogal é nasalizada, em virtude de a nasalização ser menos evidente em espanhol do que em português - é pertinente aqui referir que, segundo o estudo de Brisolara, Matzenauer e Seara (2019), a redução do valor de F1 da vogal nasalizada em relação ao valor de F1 da vogal oral é maior no português do que no espanhol. Esse dado indica que o grau de nasalização vocálica é maior no português do que no espanhol e esse fato pode implicar, para os brasileiros, dificuldade de percepção da nasalização da vogal no espanhol como LE. Este é um dado que precisa ser analisado mais detalhadamente em estudos posteriores.

Os registros dos Quadros 2 e 3 mostram, então, que, tanto para os brasileiros, quanto para os uruguaios, os índices de sucesso na percepção quando o input era a vogal oral $([\mathrm{a}] \rightarrow / \mathrm{a} /)$ foram maiores do que em input com vogais nasalizadas, sendo que ambos, brasileiros aprendizes de espanhol e uruguaios, alcançam, neste tipo de estímulo, percentuais de acerto que são próximos. 
Observe-se, no entanto, que em nenhum dos casos - estímulo com vogal oral ou estímulo com vogal nasalizada - o índice de acerto na percepção alcança o percentual de $100 \%$, o que indica a existência de variação. E essa variação que se registra na percepção dos dados linguísticos precisa ser captada na formalização aqui buscada com o suporte do BiPhon. Os percentuais registrados nos Quadros 2 e 3 alimentaram o GLA, como parte da OT Estocástica, para a avaliação dos dados à luz das restrições propostas na Seção 5 e para a sua subsequente formalização.

No Quadro 3, chama-se atenção aos índices menores de acertos na palavra 'manera', contexto nasalizado no espanhol, que teve como interpretação equivocada a vogal oral /a/ ([ã] $\rightarrow / a /)$, nos resultados dos brasileiros $(66,67 \%)$ e, especialmente, dos uruguaios $(88,89 \%)$. Tal situação demandou uma revisão dos dados e verificou-se, nessa palavra, uma diferença na duração, parâmetro acústico que orginalmente não foi buscado, uma vez que o F1 é o parâmetro suficiente para a diferenciação entre vogal oral e nasalizada. Essa revisão dos dados ensejou duas interpretações:

$\left.1^{a}\right)$ com relação à duração da vogal: em contexto de nasalização no espanhol (foi ratificada, em análise acústica, como vogal nasalizada pelo valor baixo de F1), ${ }^{22}$ a duração desta vogal foi baixa em comparação à média das durações das vogais nasalizadas no espanhol, levando a crer que a duração pode ser uma pista relevante para a percepção da nasalização vocálica;

$2^{\mathrm{a}}$ ) com relação à possibilidade de mudança na língua: em contexto de nasalização alofônica da vogal, na posição entre duas consoantes nasais, sendo a segunda nasal heterossilábica, pode estar havendo um indício de mudança no espanhol, com a eliminação dessa nasalização alofônica.

\footnotetext{
${ }^{22}$ No português brasileiro, os estudos de Cagliari (1977), Sousa (1994), Seara (2000), Souza (2013) e Santos (2013) observam que vogais nasais apresentam valores de F1 menores do que suas contrapartes orais. No espanhol, existem poucos estudos que analisam vogais nasais (BAILEY, 2013; RODRIGUES-ALVES, 2014). Destes, apenas o de Bailey (2013) contrasta vogais orais com nasais e o resultado do estudo indica uma diminuição na frequência do primeiro formante quando a vogal é nasal em contraste com a oral. O que diferencia os estudos do PB e do espanhol é que, seguindo-se os resultados encontrados em Brisolara, Matzenauer e Seara (2019, p. 18), “(...) aparentemente a distância entre esses valores de F1 não é a mesma apresentada para o PB. Essa pode ser uma particularidade da vogal nasal no espanhol".
} 
Assim, no nível da percepção, que envolve a passagem da [Forma Fonética] para a /Forma Fonológica de Superfície/, foco do estudo, as diferenças entre as línguas vão estar evidentes, sugerindo que a alofonia no fenômeno da nasalização está representada nesse nível.

\section{Formalização das Restrições}

Considerando estar no BiPhon o suporte para a análise e a formalização dos resultados do fenômeno aqui pesquisado e considerando que, como modelo de gramática, o BiPhon utiliza o modelo de avaliação do candidato a output ótimo da Teoria da Otimidade Estocástica, o estudo exigiu a determinação de restrições: Restrições de Estrutura e Restrições de Pista. Cumpre ressaltar que a gramática da língua não é representada pelas restrições em si, mas pela relação entre elas, ou seja, pela hierarquia em que as restrições estão dispostas. Explicitam-se, a seguir, as restrições que se mostraram pertinentes para a análise empreendida. Salienta-se novamente aqui, por pertinente, que no Modelo BiPhon a percepção tem natureza fonológica, sendo expressa, no Módulo da Compreensão, pela relação entre a [Forma Fonética] e a /Forma Fonológica de Superfície/, pela interação entre Restrições de Estrutura e Restrições de Pista (vejase FIGURA 1).

\subsection{Restrições de Estrutura}

As Restrições de Estrutura avaliam a /Forma Fonológica de Superfície/ e interagem com as Restrições de Pista. No caso da formalização da percepção, via Modelo Biphon, foco do estudo, conforme explicado na Seção 2.2, as Restrições de Estrutura têm a função de proibir determinada forma de output na / Forma Fonológica de Superfície /. $\mathrm{E}$ estas restrições devem lidar apenas com aquelas formas que foram previstas como candidatas, que neste trabalho foram (ver Quadros 2 e 3 ):

1) vogal oral [a] percebida como vogal oral /a/;

2) vogal oral [a] percebida como vogal nasal /ã/;

3) vogal nasal [ã] percebida como vogal oral $/ a /$;

4) vogal nasal [ã] percebida como vogal nasal /ã/. 
O entendimento dos pressupostos teóricos que dão suporte a este estudo é fator fundamental, o que justifica a Seção 2.2 do artigo. Nesse contexto, merece ser salientado que, ao tratar das restrições, a teoria deixa claro que pertencem a um conjunto universal. Buscaram-se, então, restrições que, em análises já efetuadas, mostraram estar operantes na gramática de outras línguas. Assim, tomaram-se emprestadas Restrições de Estrutura presentes em Kager (1999): as restrições * $\mathrm{V}_{\text {ORAL }} \mathrm{Ne}^{*} \mathrm{~V}_{\text {NASAL }}$ foram consideradas fundamentais para a formalização do fragmento de gramática relativo à percepção da vogal /a/ por nativos do espanhol e por brasileiros aprendizes da língua, conforme está expresso em (1):

(a) $* \mathrm{~V}_{\text {ORAL }} \mathrm{N}=$ São proibidas vogais orais diante de consoante nasal tautossilábica. (KAGER, 1999, p.28)

(b) $* \mathrm{~V}_{\mathrm{NASAL}}=$ São proibidas vogais nasais. (KAGER, 1999, p. 28)

A restrição $* \mathrm{~V}_{\text {NASAL }}$ é capaz de captar a ideia universal de que não há línguas que possuam apenas vogais nasalizadas (GOUSKOVA, 2009). Logo, prever restrição contra a nasalização vocálica versus contra vogal oral é o primeiro passo para a formalização do fenômeno aqui sob análise, com a comparação de duas línguas: português e espanhol. Neste caso, é uma restrição que deve receber um valor central alto, considerando-se que, tanto para os nativos do espanhol, quanto para os brasileiros aprendizes desta língua, a percepção da vogal nasalizada pareceu mais custosa ou mais marcada.

Já a restrição $* \mathrm{~V}_{\text {ORAL }} \mathrm{N}$, que proíbe vogais orais diante de consoante nasal, em contexto tautossilábico, é relevante para diferenciar aqueles casos, no português, em que a vogal nasalizada pode ter cunho fonológico, o que de fato ocorreu nos dados mostrados nos Quadros 2 e 3. Assim, o esperado é que a posição desta restrição na gramática dos nativos de espanhol esteja em posição alta na hierarquia, isto é, que tenha pesos maiores, que demonstrem que a sua proibição tem uma eficácia maior na emergência de vogal nasal na/Forma Fonológica de Superfície/, já que o espanhol não apresenta nasalidade vocálica fonológica.

\subsection{Restrições de Pista}

As Restrições de Pista, diferentemente das Restrições de Estrutura, avaliam pistas fonéticas específicas de língua na interação entre os níveis 
fonético e fonológico. Penalizam o desvio entre a /Forma Fonológica de Superfície/ (output da percepção) e a [Forma Fonética] (input da percepção) e são lidas da seguinte forma: não perceber os estímulos produzidos ([pistas acústicas]) como uma /vogal oral/nasalizada/.

Assim, estas restrições devem prever todas as possibilidades de relação input-output, consideradas no fragmento da gramática em foco e representadas nos Quadros 2 e 3. Em (2), estão as seis Restrições de Pista utilizadas na análise aqui proposta.

(a) $*[\mathrm{~F} 1 \sim 728 \mathrm{~Hz}] / \mathrm{a}+$ nasal$/ \rightarrow *[\tilde{\mathrm{a}}] / \tilde{\mathrm{a}} /$

(b) $*[\mathrm{~F} 1 \sim 728 \mathrm{~Hz}] / \mathrm{a} / \quad \rightarrow *[\tilde{a}] / \mathrm{a} /$

(c) $*[\mathrm{~F} 1 \sim 848 \mathrm{~Hz}] / \mathrm{a} / \rightarrow *[\mathrm{a}] / \mathrm{a} /$

(d) $*[\mathrm{~F} 1 \sim 848 \mathrm{~Hz}] / \mathrm{a}+\mathrm{nasal} / \rightarrow *[\mathrm{a}] / \tilde{\mathrm{a}} /$

(e) $*[$ Duração $<0,1 \mathrm{~s}] / \mathrm{a} / \quad \rightarrow *[\mathrm{a}] / \mathrm{a} /{ }^{23}$

(f) $*$ [Duração $<0,1 \mathrm{~s}] / \mathrm{a}+$ nasal $/ \rightarrow$ [a] $/ \tilde{a} /$

Os valores de F1 e de duração foram tomados como pistas relevantes para a análise. Esses valores referentes à vogal /a/ nos diferentes contextos foram extraídos das médias das produções dos dois locutores que gravaram as palavras listadas no Quadro 1, para a elaboração do teste de percepção. Essas informações acústicas foram comparadas aos dados obtidos em Brisolara, Matzenauer e Seara (2019) para que se pudesse estabelecer um parâmetro sobre as produções das pistas de vogal /a/ com nasalização e sem nasalização.

A pista destacada na análise para diferenciar acusticamente a vogal oral da vogal nasalizada foi a redução do primeiro formante (DELATTRE, 1954), considerada a característica proeminente nos estudos sobre nasalidade vocálica em termos acústicos, conforme já referido na Seção 4.

Dessa forma, os limites de F1 da vogal/a/, registrados pelas médias F1 728hz e F1 848hz deveriam estabelecer que os sons com F1 mais baixos (F1 $\sim 728 \mathrm{hz})$ fossem interpretados como vogal nasal e os sons com F1 mais altos (F1 $\sim 848 \mathrm{hz})$, como oral. Entretanto, os

${ }^{23}$ As Restrições de Pista da duração foram utilizadas para explicar a duração baixa do estímulo da palavra 'manera'. 
resultados apresentados nos Quadros 2 e 3 parecem mostrar que outras variáveis acústicas, ou mesmo fonológicas, também podem influenciar na percepção da vogal em contexto nasal. Destaca-se, assim, o registro da duração como outro parâmetro acústico, ou pista acústica, também relevante para formalizar a percepção da vogal em contexto de nasal, neste estudo, pois os valores da duração da locutora na palavra 'manera' ficaram muito abaixo do esperado para uma vogal nasal, mesmo em contexto heterossilábico. ${ }^{24}$

\section{Simulações de Gramáticas}

Em virtude de o BiPhon utilizar, para o mapeamento entre o input e o output, o modelo de avaliação de restrições da OT Estocástica, a qual inclui o GLA, conforme já anteriormente explicitado, os dados precisaram ser abordados por meio de simulações computacionais de gramáticas.

Diante do fenômeno objeto de análise na investigação aqui relatada - a nasalidade da vogal /a/ - brasileiros aprendizes de espanhol e uruguaios falantes nativos dessa língua apresentam diferentes gramáticas, o que está expresso na formalização dos tableaux de 1 a 4 .

Como o foco deste estudo está na percepção, a análise ficou centrada no Módulo da Compreensão do BiPhon, modelo de gramática que propõe que as formas de output observadas na língua surgem da satisfação de um conflito de restrições (veja-se FIGURA 1).

Além disso, a partir deste Modelo Bidirecional, a gramática vai definir também a distribuição da probabilidade da ocorrência de cada output; os valores centrais das restrições (ranking values), mais altos ou mais baixos, vão representar aquelas restrições que vão estar, mais vezes, acima ou abaixo na hierarquia, possibilitando que se faça diferença na probabilidade de ocorrência levantada para a emergência dos candidatos na superfície (vogal oral ou nasalizada).

Nos "Tableaux de percepção" 1 e 2, apresentados a seguir, são mostradas duas rodadas dos dados obtidos junto aos brasileiros aprendizes de espanhol e, nos "Tableaux de percepção" 3 e 4, apresentados a seguir, trazem-se duas rodadas dos dados obtidos junto aos uruguaios. São aqui

\footnotetext{
${ }^{24}$ Como a metade das palavras incluídas no Teste de Identificação foi retirada do locutor do sexo feminino e a outra metade do locutor do sexo masculino, a palavra 'manera' inserida no teste foi a gravada pela locutora.
} 
registradas duas rodadas de cada um dos dois grupos de informantes, a fim de exemplificar-se a escolha de diferentes outputs a partir de estímulos com a presença da vogal /a/ do espanhol no contexto de consoante(s) nasal(is). As diferentes rodadas para cada grupo de informantes mostram a variação linguística na percepção da nasalidade alofônica no espanhol por brasileiros e uruguaios. Observe-se ainda que os tableaux, todos apresentados na Seção 6.1, trazem apenas dois candidatos a output, ou seja, apenas as formas que, variavelmente, foram percebidas pelos informantes da pesquisa.

Reitera-se que, no modelo Biphon, tal como na Teoria da Otimidade, a gramática das línguas é um conjunto de restrições e o que as diferencia é a hierarquia. Assim, enquanto a escolha das restrições é fundamental na descrição do processo fonológico, a interação entre as restrições é fundamental na formalização dos fenômenos. A escolha pelo modelo Biphon na presente análise, com o uso OT Estocástica, que está vinculada a um Algoritmo de Aprendizagem Gradual, está na possibilidade de ficarem demonstradas as variações apresentadas nos outputs dos participantes da pesquisa, na percepção da nasalidade vocálica.

Conforme demonstrado nos Quadros 2 e 3, os participantes brasileiros, aprendizes de espanhol, apresentaram maior facilidade em perceber inputs nasalizados. Tal resultado se apresentará em forma de restrições que proíbem ou permitem a presença de vogais nasais no output da percepção e nas suas relações variáveis. Assim, em uma relação direta, quanto mais próximos os pesos centrais (ranking value) das restrições que proíbem e permitem a emergência da vogal nasal, maior é a variação dos outputs com e sem a vogal nasal. A informação sobre quão frequente é esta variação e qual output emerge como candidato ótimo mais vezes é explicada, também, pelo peso das restrições. Aquelas restrições com valores maiores no ranking value estarão mais vezes acima, na hierarquia, impedindo candidatos a output de emergirem.

\subsection{A gramática da LE dos brasileiros aprendizes de espanhol}

Apresenta-se, a seguir, a formalização do fragmento da gramática do espanhol como LE dos brasileiros aprendizes de espanhol, com relação ao foco do presente estudo, por meio dos Tableaux de percepção 1 e 2 .

Na percepção da vogal nasalizada no espanhol, as possibilidades de candidatos esperadas foram extraídas dos percentuais das respostas do Teste de Identificação, expostas nos Quadros 2 e 3. 
Os dados evidenciam que, diante das formas fonéticas ouvidas (sejam de vogal oral ou nasalizada), a percepção dos brasileiros pode levar à categorização como /Forma Fonológica/ oral (/a/) ou nasalizada (/ã/).

Os processos de alternâncias alofônicas nas línguas, seja em dados de variação ou dados de aquisição, são alvo de discussão à luz de modelos fonológicos. E quando é proposta uma análise a partir de um modelo com três níveis de representação, sendo dois fonológicos e um estritamente fonético, é assumida uma explicação menos tradicional em modelos fonológicos, conforme se verá a seguir.

Primeiramente é formalizada a simulação da percepção da vogal como segmento oral; veja-se o Tableau de Percepção $1-1^{\text {a }}$ Rodada.

TABLEAU DE PERCEPÇÃO 1 - Fragmento da gramática da LE dos Brasileiros $-1{ }^{\mathrm{a}}$ Rodada - percepção da vogal como segmento oral

\begin{tabular}{|c|c|c|c|c|c|c|c|c|}
\hline \multicolumn{2}{|c|}{ maving valise dithanomy } & \multirow{2}{*}{\multicolumn{7}{|c|}{$\begin{array}{l}\text { plestitily } \\
1000000\end{array}$}} \\
\hline 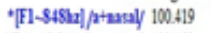 & 1035541000 & & & & & & & \\
\hline 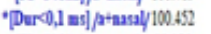 & 10271 & \multicolumn{7}{|c|}{$\begin{array}{l}10000 \\
100000\end{array}$} \\
\hline 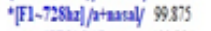 & 102306 & \multicolumn{7}{|c|}{1000000} \\
\hline "TXSAL 100.29 & 101555 & \multicolumn{7}{|c|}{100000} \\
\hline$\cdot[11-848 k 1] / 2 y \quad 99591$ & 100.02 & \multicolumn{7}{|c|}{1000000} \\
\hline$\cdot[11-728 \mathrm{kr}] / 21 / 100125$ & 99995 & \multicolumn{7}{|c|}{100000} \\
\hline "TORALX 99.64 & 9817 & \multirow{2}{*}{\multicolumn{7}{|c|}{$\begin{array}{l}1000000 \\
1000000\end{array}$}} \\
\hline 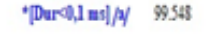 & 9995 & & & & & & & \\
\hline [landudf & 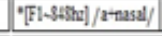 & 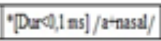 & 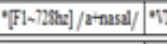 & "TXASAL |" & {$[F 1-4+5 h x] / 2 /[\cdot[F l$} & \multicolumn{3}{|c|}{ 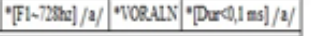 } \\
\hline \multicolumn{2}{|l|}{ 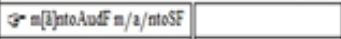 } & & & & & $\cdot$ & $\cdot$ & \\
\hline \multicolumn{2}{|l|}{$\mathrm{m}[\mathrm{i}$ thtodvd $\mathrm{m} / \mathrm{i} / \mathrm{intoSF}$} & & "1 & $\cdot$ & & & & \\
\hline$[n n]$ tudf & 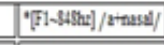 & 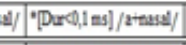 & 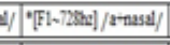 & " भXASAL & 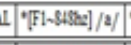 & $2 /[7[1-725 h t] / 2 /]$ & TroraLs" & ["Purot,1 as]/:2/ \\
\hline \multicolumn{2}{|l|}{ 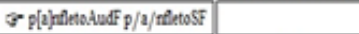 } & & & & $\cdot$ & & $\cdot$ & \\
\hline 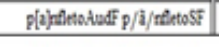 & $" 1$ & & & $\cdot$ & & & & \\
\hline [2al|Audf & "[F1-34Sh]/2-2asad/]" & 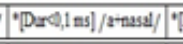 & 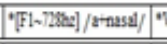 & "IXASAL|" & 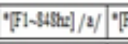 & "[F1-725h]/a/] & MORALN|'[1] & 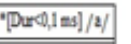 \\
\hline 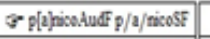 & & & & & $\cdot$ & & & \\
\hline$p[$ lapioodudF $\mathrm{p} / \mathrm{i} /$ tizoSE & ?! & & & $\cdot$ & & & & \\
\hline [In] tusf & 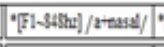 & 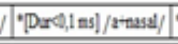 & 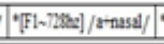 & "ขNAS.AL & 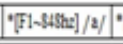 & 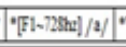 & mORALII. & {$[$ [Duro, $1=s] / 2 /$} \\
\hline 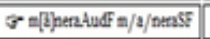 & & & & & & $\cdot$ & & $\overline{1}$ \\
\hline m[lihendudf $\mathrm{m} / \mathrm{a} / \mathrm{ntenSF}$ & & "! & $\cdot$ & $\cdot$ & & & & \\
\hline [a],Auf & 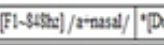 & "Puro,1ss]//rnass]/"| & 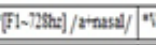 & FXXSAL $\mid$ "F & 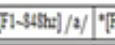 & 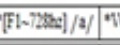 & MORALN] "I & Dros,1 as]/2/ \\
\hline 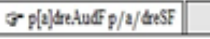 & & & & & $\cdot$ & & & $\cdot$ \\
\hline
\end{tabular}

Fonte: As autoras 
Esse primeiro Tableau de percepção representa uma simulação da formalização das restrições em um momento no qual os participantes do Teste de Identificação estão interpretando todos os sons [a] do espanhol como oral, mesmo que tenham sido produzidos como nasalizados pelos locutores.

$\mathrm{O}$ input está representado na primeira coluna do Tableau ${ }^{25}$ as restrições estão organizadas de acordo com o valor disharmony (valor de seleção) e o output ótimo está indicado, também na primeira coluna, com a notação $\sigma^{*}$, que representa um momento de produção linguística. As restrições, quanto mais à esquerda, mais acima no ranking estão, e foram organizadas automaticamente pelo software PRAAT, de acordo com os pesos disharmony, que podem variar a cada produção (rodada do sistema).

Neste caso, as restrições que proíbem a vogal nasal no output, impedindo a emergência deste tipo de candidato como ótimo, são promovidas; são Restrições de Pista e uma Restrição de Estrutura: $*[\mathrm{~F} 1 \sim 848 \mathrm{hz}] / \mathrm{a}+$ nasal/; $*$ [F1 728hz $] / \mathrm{a}+$ nasal/; $* \mathrm{~V}_{\mathrm{NASAL}}$. A exceção desta organização nas restrições ocorre naquele input que teve o pequeno valor de duração para a vogal, no input ('manera'), aparentemente influenciando no resultado da percepção. Para os candidatos a output advindos deste input, a Restrição de Pista *[Dur $<0,1 \mathrm{~s}] / \mathrm{a}+$ nasal/ foi relevante e assumiu uma posição alta no ranking.

De acordo com os pressupostos teóricos do Algoritmo de Aprendizagem Gradual (GLA), utilizado no modelo por estar vinculado à OT Estocástica, reforça-se aqui que os valores centrais devem permanecer os mesmos nas simulações dos diversos momentos de percepção; o que vai mudar são os pontos de seleção (disharmony), de forma a demonstrar como se dá a ocorrência de candidatos variáveis, motivo pelo qual se apresentam dois Tableaux de Percepção para formalizar tanto a percepção dos brasileiros, como, depois, a percepção dos uruguaios.

Destaca-se a inclusão do último Tableau com a palavra 'padre', ${ }^{26}$ que atendeu ao objetivo de demonstrar que a versão nasal ocorre em

${ }^{25} \mathrm{O}$ valor de plasticidade apresentado junto aos valores disharmony e ranking value representa a taxa de incremento/decremento do algoritmo. O valor utilizado, igual a 1,000000 , é o valor default do software e pode ser alterado pelo pesquisador.

${ }^{26}$ Foram também gravadas pelos locutores palavras que não continham nenhuma consoante nasal próxima à vogal baixa, mas estas não foram usadas nos estudos de Brisolara e Matzenauer (2018a, 2018b). 
contexto com a consoante nasal, mas que a versão oral ocorre em qualquer contexto. Neste caso, a opção será sempre pelo candidato fiel, definido pelas Restrições de Pista.

Em uma segunda rodada, o Tableau de percepção dos brasileiros vai representar um segundo momento na percepção dos sons, em que há outras possibilidades de output ótimo, ou seja, há variação na percepção (com a vogal nasalizada ou com a vogal oral), mesmo diante de inputs com a vogal oral.

TABLEAU DE PERCEPÇÃO 2 - Fragmento da gramática da LE dos Brasileiros

$-2^{\mathrm{a}}$ Rodada - percepção variável da vogal (ora como segmento oral, ora como segmento nasalizado)

\begin{tabular}{|c|c|c|c|c|c|c|c|c|}
\hline nenkigg ve & Whe dipharm & move & pleficity & & & & & \\
\hline 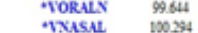 & 4 1045t & 1517 & $\begin{array}{l}1.0000000 \\
10000000\end{array}$ & & & & & \\
\hline$\cdot[\mathrm{F} 1-728 \mathrm{kz}] / \mathrm{sy} \quad 100.125$ & $5 \quad$ 100.52 & 528 & 1000000 & & & & & \\
\hline 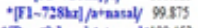 & wh. & & 1000000 & & & & & \\
\hline 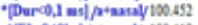 & 10092 & & 10000000 & & & & & \\
\hline 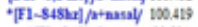 & 9019: & & 1000000 & & & & & \\
\hline "[F1-st5ha]/Ay 90581 & 9787 & & 10000000 & & & & & \\
\hline 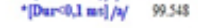 & 9676 & 762 & 1000000 & & & & & \\
\hline [n]hudf & "rorals. & misusta & 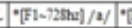 & 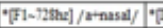 & 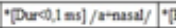 & 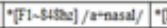 & 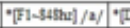 & "Durro, 1 $\mathbf{m s} / \mathbf{a} /$ \\
\hline 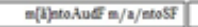 & 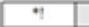 & & - & & & & & \\
\hline 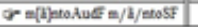 & & $\cdot$ & & $\cdot$ & & & & \\
\hline$[\mathrm{m}$ Audf & MORAL & IN $\mid \cdot$ IXASA & SAL $\mid \cdot$ F1-72the] $/ \mathrm{a} /$ & 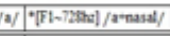 & 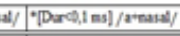 & 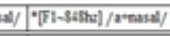 & 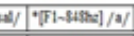 & a/] $[$ Paxal, $1 \mathrm{~ms}] / \mathrm{a} /$ \\
\hline 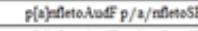 & $\theta$ & & & & & & - & \\
\hline 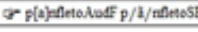 & & $\cdot$ & & & & $\cdot$ & & \\
\hline [an]AudF & "Worals] & WXASAL & 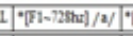 & 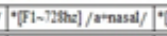 & 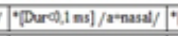 & 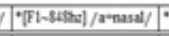 & 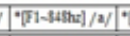 & 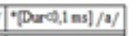 \\
\hline 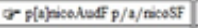 & & & & & & & * & \\
\hline D(a)nicatedf $\mathrm{p} / \mathrm{l} / \mathrm{n}$ icosf & & $\because$ & & & & $\cdot$ & & \\
\hline [in\}Aud & "NoralN & "WNASAL & 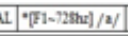 & 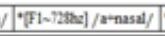 & 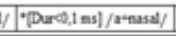 & 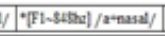 & 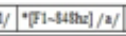 & 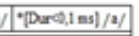 \\
\hline 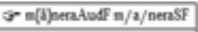 & & & $\cdot$ & & & & & $\cdot$ \\
\hline$=(1)$ peratodf $\mathrm{a} / \mathrm{l} / \mathrm{nen} \mathrm{SF}$ & & 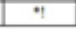 & & $\cdot$ & $\cdot$ & & & \\
\hline [a]hu\& & 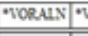 & "rxasal" & 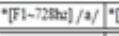 & "[71-72sht]/arnasal/ [" & 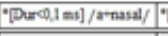 & "[Fl-Sistar]/arnasal/" & {$[\mathrm{F} / \mathrm{s}(\mathrm{sh}) / \mathrm{a} /]^{2}$} & "Durcal, $1=\mathrm{s}] / \mathrm{s} / \mathrm{s}$ \\
\hline or plajtretudf $p / a /$ destF & & & & & & & - & - \\
\hline
\end{tabular}

Fonte: As autoras

Neste segundo Tableau de percepção, nos casos em que o output da percepção é vogal nasal (como em 'manto' e 'panfleto'), ${ }^{27}$ tem-se a restrição $* \mathrm{~V}_{\mathrm{ORAL}} \mathrm{N}$ promovida na hierarquia, marcando uma relação

${ }^{27}$ Nota-se que, no Tableaux de Percepção 2, mesmo em palavras que na língua espanhola não há nasalização, como em "panfleto", o output da percepção é de uma vogal nasalizada. 
entre as restrições, diferente da que foi apresentada na primeira rodada da percepção para os brasileiros ${ }^{28}$ (Tableau de percepção 1).

Por outro lado, o fato de a Restrição de Marcação * $\mathrm{V}_{\text {NASAL }}$ (100.294) e as Restrições de Pista *[Dur $<0,1 \mathrm{~s}] / \mathrm{a}+$ nasal/ $(100.452)$ e $*[\mathrm{~F} 1 \sim 848 \mathrm{hz}] / \mathrm{a}+$ nasal/ (100.419) apresentarem valores centrais mais altos informa que os candidatos com output oral são mais frequentes, pois têm menor possibilidade de ser proibidos, ou seja, têm mais chance de emergirem como ótimos.

Os dados dos estudantes brasileiros evidenciaram maior índice de variação na percepção de inputs com vogal nasalizada do que ao se depararem com inputs com vogal oral. Este resultado pode estar ligado ao fato de a vogal /a/, altamente não marcada nas línguas, ser perceptualmente menos desafiadora do que uma vogal nasal (CROSSWHITE, 2001; LINDBLOM, 1986), mas também pode ser explicado por, no português, a nasalidade poder ser fonológica no grupo VN ("manta"). Além disso, pode ser decorrente do fato de a duração das vogais nasalizadas no espanhol terem duração menor do que se verifica no português (vejase Seção 4). Ainda pode estar vinculado à pressuposição, a partir de orientações generalizantes recebidas em sala de aula de espanhol, de que nessa língua não são produzidas vogais nasalizadas.

Tal situação está representada, na formalização dos Tableaux de percepção 1 e 2, na posição que as Restrições de Estrutura assumem no ranking correspondente à gramática da $\mathrm{LE}$ dos brasileiros aprendizes de espanhol. De forma muito sutil, a hierarquia de restrições que representa a gramática dos brasileiros para o fenômeno aqui estudado demonstra que as Restrições de Estrutura recebem pesos que permitem a emergência da vogal nasalizada no /output/ da percepção, ou seja, na/Forma Fonológica de Superfície/, especialmente naqueles casos em que o contexto é VN.

Nesse sentido, as Restrições de Estrutura, na gramática dos brasileiros, assumem posições mais centrais na hierarquia, de forma a permitir a emergência mais frequente de outputs da percepção com a vogal nasal. Interpreta-se, portanto, que esse resultado é motivado pelo fato de, ao se deparar com uma construção incomum no processo de aquisição de uma LE, o ouvinte a detectará e resolverá a questão de acordo com as normas de sua língua materna. Esse fato implica que a

\footnotetext{
${ }^{28}$ Ressalta-se que as diferenças com relação à hierarquia apresentada nos Tableau de percepção 1 e 2 somente ocorreram, porque a distância entre os valores centrais das restrições era inferior a 10 pontos.
} 
percepção é fonológica e está representada pela interação entre Restrições de Pista e de Estrutura.

Passa-se agora à formalização da gramática dos uruguaios, com relação ao objeto de estudo aqui proposto, por meio dos Tableaux de percepção 3 e 4 .

\subsection{A gramática dos uruguaios}

No nível da percepção dos participantes uruguaios, as possibilidades de candidatos esperadas foram extraídas das respostas do Teste de Identificação, expostas nos Quadros 2 e 3.

Formaliza-se, inicialmente, a simulação da percepção da vogal como segmento oral pelos informantes uruguaios; veja-se o Tableau de Percepção $3-1^{\text {a }}$ Rodada, que apresenta o fragmento da gramática relativa ao foco do presente estudo.

TABLEAU DE PERCEPÇÃO 3 - Fragmento da gramática dos Uruguaios $-1^{a}$ Rodada - percepção da vogal como segmento oral

\begin{tabular}{|c|c|c|c|c|c|c|c|c|}
\hline \multirow{2}{*}{\multicolumn{2}{|c|}{ rJXtStL ranking valing }} & dithermony & \multicolumn{6}{|c|}{ plestikity } \\
\hline & \multicolumn{2}{|c|}{102342} & \multicolumn{6}{|c|}{$\begin{array}{l}\text { Plestivity } \\
1000000\end{array}$} \\
\hline -VORALIT 100.737 & \multicolumn{2}{|c|}{101.127} & \multicolumn{6}{|c|}{1000000} \\
\hline "[F1-728ha]/2+asaly 100844 & \multicolumn{2}{|c|}{100.58} & \multicolumn{6}{|c|}{1000000} \\
\hline$+[1-8454 x] / 2+\operatorname{tasaly} 100181$ & \multicolumn{2}{|c|}{100381} & \multicolumn{6}{|c|}{1000000} \\
\hline •[Dur<0,1 ms] /2+axal/101352 & 985909 & 1000 & \multicolumn{6}{|c|}{1000000} \\
\hline${ }^{\circ}[\mathrm{Der}(0,1 \mathrm{n}=1 / 2 \mathrm{~g} \quad 98.648$ & 97.683 & 1000 & \multicolumn{6}{|c|}{1000000} \\
\hline '[F1-728tan]/4y $\quad 99.156$ & 96050 & 1000 & \multicolumn{6}{|c|}{1000000} \\
\hline$\cdot[11-848 \mathrm{tr}] / 2 / \quad 99.819$ & 95314 & \multicolumn{7}{|c|}{1000000} \\
\hline [inj|Aodf & \begin{tabular}{|l|l|l|} 
"IXASAL & " \\
\end{tabular} & 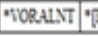 & 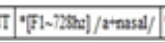 & 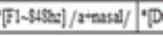 & "Dare,1 ms]/zrnass/] "7. & 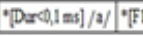 & 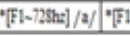 & {$[71-34502] / 2 /$} \\
\hline 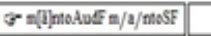 & & $\bar{*}$ & & & & & $\cdot$ & \\
\hline 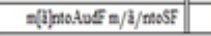 & 甲! & & $\cdot$ & & & & & \\
\hline [an]/udF & "WASAL & \begin{tabular}{l|l|l|l|l|l|} 
AL & TORALNT \\
\end{tabular} & 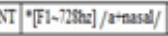 & 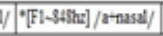 & 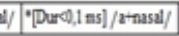 & 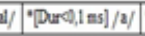 & 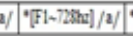 & 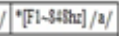 \\
\hline 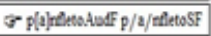 & & $\cdot$ & & & & & & $\cdot$ \\
\hline 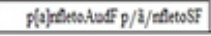 & "1 & & & $\cdot$ & & & & \\
\hline [2n]AdedF & "TXASAL |" & "NORALIT:" & 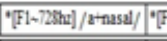 & 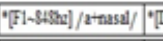 & [Dar00,1 ms]/arasd/] ["] & [Dur<0,1 ass]/a/ $\mid \cdot[\mathbb{F}$ & "[F1-728hs]/a/ $\mid \cdot[F$ & {$[F 1-818 \mathrm{~B}] / 2 /$} \\
\hline 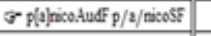 & & & & & & & & $\cdot$ \\
\hline Plahrico,Audf $\mathrm{p} / \mathrm{i} /$ ascoss & \%1 & & & $\cdot$ & & & & \\
\hline [3n]Aud & "NXASAL & \begin{tabular}{|l|l|} 
NORALNT & \\
\end{tabular} & 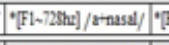 & 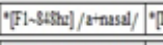 & |[Dar<0,1 Ins]/arasul/ & 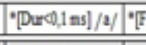 & "[F1-728ka]/a/ $[\cdot[\mathrm{F}$ & -[Fl-S15ht]/2/ \\
\hline 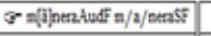 & & & & & & $\cdot$ & $\cdot$ & \\
\hline 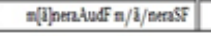 & $\because$ & & $\cdot$ & & $\cdot$ & & & \\
\hline
\end{tabular}

\begin{tabular}{|c|c|c|c|c|c|c|c|c|}
\hline [a]Aus & -IXASAL & FORALIT & ["[F1-728ca] / a-nass]/ & "[F1-S4the]/a+natal/ & [PurQ, I ms]/2-nasal/ & [Daro, 1 $=3] / 2 /$ & "[?]1-72sht]/2/ & "[F1-34ths] / / / \\
\hline of $p[a] d e d$ dudF $p / a /$ dreSF & & & & & & $\cdot$ & & 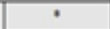 \\
\hline
\end{tabular}

Fonte: As autoras 
Seguindo o mesmo tratamento dado à formalização da percepção da LE dos brasileiros aprendizes de espanhol, esse primeiro tableau de percepção dos uruguaios representa um momento no qual os participantes do Teste de Identificação estão interpretando todas as ocorrências de [a] como oral, mesmo que tenham sido produzidas como nasalizadas pelos locutores.

A identificação em maior número da vogal /a/ como oral, mesmo em contexto nasal, está representada pelo peso recebido pela Restrição de Estrutura * $\mathrm{V}_{\text {NASAL }}(101.024)$, que impede que os outputs da percepção com a vogal nasalizada apareçam, ou seja, que possibilita que outputs da percepção com a vogal oral emerjam de forma mais frequente.

Destaca-se, neste ponto, que a presença da categorização, no / output/ da percepção, de vogal nasalizada não implica que a gramática do espanhol tenha vogais nasais, mas que categoriza, como um movimento fonético-fonológico desse sistema linguístico, a possibilidade de nasalização da vogal em contexto de consoante nasal, isto é, argumentase a favor de a alofonia estar presente no nível fonológico de superfície, que reúne a passagem da informação estritamente fonética para a categorização fonológica, ainda sem acesso ao léxico.

O Tableau de Percepção 4 formaliza, em uma segunda rodada, a percepção variável que os uruguaios apresentam: mesmo diante de inputs com a vogal oral, variavelmente podem escolher diferentes /outputs/ da percepção com a vogal nasalizada ou com a vogal oral. 
TABLEAU DE PERCEPÇÃO 4 - Fragmento da gramática dos Uruguaios $-2^{\mathrm{a}}$ Rodada - percepção variável da vogal (ora como segmento oral, ora como segmento nasalizado)

\begin{tabular}{|c|c|c|c|c|c|c|c|c|}
\hline 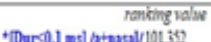 & dus dethernow $f$ & \multicolumn{7}{|l|}{ plestiving } \\
\hline "Dur $0,1 \mathrm{~ms}] / 2 \operatorname{tanal} / 101332$ & 103,750 & 1000000 & & & & & & \\
\hline 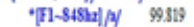 & wases & 1000000 & & & & & & \\
\hline TXXSAL toLo24 & 100.347 & 1000000 & & & & & & \\
\hline 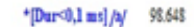 & 99920 & 1.000000 & & & & & & \\
\hline "TORALAT 100.737 & 98.54 & 1000000 & & & & & & \\
\hline 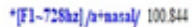 & 972 & 1.000000 & & & & & & \\
\hline "[F1-845tz]/2+asaly 100181 & s8610 & 1000000 & & & & & & \\
\hline '[F1-7281x]/3/ 99.156 & 98.48 & 1000000 & & & & & & \\
\hline [lephud & 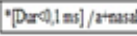 & al/ $[$ Fi-Staht]/a/] & "NASAL & 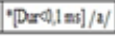 & FCralst & [Fl-72the]/z-anal/] & ["F1-3+thy]/arnassl] & [Fl-72tas]/2/ \\
\hline$\checkmark=[$ l]ptodudf $\mathrm{m} / \mathrm{a} / \mathrm{att}$ SE & & & & & $\cdot$ & & & $\cdot$ \\
\hline$=[$ lihtadudf $\mathrm{m} / \mathrm{z} / \mathrm{et} 0 \mathrm{SE}$ & & & "! & & & $\cdot$ & & \\
\hline
\end{tabular}

\begin{tabular}{|c|c|c|c|c|c|c|c|c|}
\hline [n],Aadf & "[DarQ,1 as]/2rnas/] & "[F1-34thr]/2/ & "IXASAL & [Daro,1 as] /2/ & FORALIT & 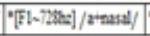 & 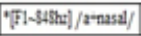 & 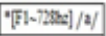 \\
\hline 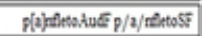 & & ๆ & & & $\bar{*}$ & & & \\
\hline 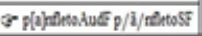 & & & $\cdot$ & & & & $\cdot$ & \\
\hline
\end{tabular}

\begin{tabular}{|c|c|c|c|c|c|c|c|c|}
\hline$[2 n)+4 u \in f$ & 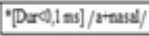 & [F1-SASht]/2/ & "IXASAL & [Dand,1 $1 \mathrm{~s}] / 2$ ] & MORALIT & "[Fl-72hs]/2-assal] & [F1-StSh]/arnasu/] & [Fl-725ta]/2/ \\
\hline plapico.tus $\mathrm{p} / 2 /$ mincosf & & थ! & & & & & & \\
\hline 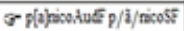 & & & $\cdot$ & & & & $\cdot$ & \\
\hline
\end{tabular}

\begin{tabular}{|c|c|c|c|c|c|c|c|c|}
\hline [iephudf & [Drol,1 as] / a rasal/ & "Fl-34Sh]/2/ & "NASAL & 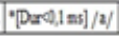 & Foralst & 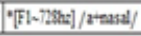 & [F1-345h]/2-nasal/] & "[Fl-725te]/a/ \\
\hline 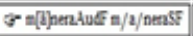 & & & & $\overline{ }$ & & & & $\overline{ }$ \\
\hline 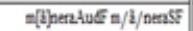 & 甲! & & $\cdot$ & & & $\cdot$ & & \\
\hline
\end{tabular}

\begin{tabular}{|c|c|c|c|c|c|c|c|c|}
\hline [a], tudf & 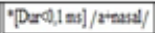 & 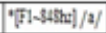 & "IXASAt & "Dero, 1ss] /2/ & 708ALAT & 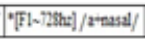 & 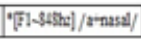 & 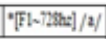 \\
\hline 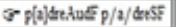 & & - & & - & & & & \\
\hline
\end{tabular}

Fonte: As autoras

Na gramática dos uruguaios, as Restrições de Estrutura assumem posições um pouco mais altas no ranking (valores centrais maiores) em comparação com a gramática da LE dos brasileiros, informando que, nesta variedade do espanhol, a opção é pela vogal oral, menos marcada nas línguas.

Os dados mostraram que, diante de um [input] com uma vogal nasalizada, os uruguaios, na maioria das vezes, perceberam a vogal como oral, isto é, a fonologia da língua, com a promoção das Restrições de Estrutura no ranking, fez com que os uruguaios bloqueassem a possibilidade de /outputs/ da percepção fieis à forma nasalizada.

Esse fato implica que, na passagem da /Forma Fonológica de Superfície/ para a |Forma Subjacente| (módulo estritamente fonológico), a categorização da vogal, tanto no português como no espanhol, será exclusivamente oral. 
Dessa forma, a representação aqui formalizada para a percepção das vogais com e sem a nasalização segue o princípio de que todas as restrições são relevantes para a análise e apresentam valores próximos, tendo em vista que todas as possibilidades de candidatos propostas são possíveis. No entanto, destaca-se que há uma relação marcada entre as Restrições de Pista e de Estrutura, que indica a relevância entre a escolha de uma ou outra forma.

Em síntese, têm-se, nos Tableaux de percepção 3 e 4, a formalização e a explicitação, por meio de restrições, dos resultados percentuais registrados nos Quadros 2 e 3, entendendo-se por que os uruguaios percebem e categorizam na /Forma Fonológica de Superfície/ em grande parte das vezes um /output/ da percepção que é oral.

Há um destaque para a relevância das Restrições de Pista, que vão assumir os pesos com valores mais altos, evidenciando, portanto, que o fenômeno da nasalização, no espanhol, demanda o relacionamento importante com a manifestação fonética que ocorre em determinados contextos.

Ao mesmo tempo, observa-se a proximidade dos valores centrais apresentados pelas Restrições de Estrutura e de Pista, revelando que as restrições fonológicas também assumem papel em alguns momentos na explicação da nasalização da vogal /a/, especialmente diferenciando os resultados obtidos nos contextos tautossilábicos e heterossilábicos.

Pela variação que os dados mostraram, era de esperar-se que os valores centrais das restrições fossem tão próximos que possibilitassem a emergência de todos os candidatos. Assim, não há uma restrição altamente ranqueada, com valor central bem superior às demais restrições. Essa situação advém de dois fatos, um empírico e outro formal:

(a) os acertos, no teste de percepção de vogais em contextos de nasalização, não alcançaram $100 \%$, o que evidencia que realmente há variação na percepção de vogais nasalizadas;

(b) na formalização dos dados por meio de tableaux não foi previsto nenhum candidato que não possa ser encontrado nos dados.

Como consequência do item (b), todos os candidatos efetivamente ocorrem de forma variável. Poderiam ter sido propostos candidatos impossíveis, para demonstrar que há, na gramática, alguma forma de dominância sem possibilidade de variação, entretanto a criação de mais 
candidatos demandaria mais restrições fonéticas; por isso optou-se por manter, na análise, apenas os candidatos cuja escolha como ótimo é possível.

\section{Conclusão}

Com o suporte do Modelo BiPhon, foi respondida a primeira questão proposta para a pesquisa sobre a percepção de vogais nasalizadas no espanhol: falantes nativos do português do Brasil, no processo de aquisição do espanhol como LE, alcançaram maior sucesso na percepção de vogais nasalizadas presentes no espanhol do que uruguaios, falantes nativos desta língua; sendo assim, são evidenciados comportamentos distintos, quanto ao fato aqui estudado, entre uruguaios e brasileiros aprendizes de espanhol. A formulação dessa questão foi motivada pelo entendimento de que a percepção é fonológica, resultante, à luz do BiPhon, do mapeamento de [Forma Fonética] em /Forma Fonológica de Superfície/.

Sob a luz dos pressupostos desse modelo, também foi respondida a segunda questão, sendo formalizada a percepção como o mapeamento entre o continuum fonético e o discreto fonológico, caracterizando e representando a diferente gramática dos uruguaios e da LE dos brasileiros aprendizes de espanhol, quanto à percepção da vogal /a/ nasalizada, pela interação entre Restrições de Pista e Restrições de Estrutura.

Basicamente procurou-se mostrar que a diferença está no peso central das Restrições de Estrutura. Considerando que, no português, a nasalidade pode ser fonológica, como em "manta", ou alofônica, como em "pânico", distintamente do espanhol, a representação mostrou-se diferenciada em falantes de uma e de outra língua.

Este condicionamento fez com que a restrição que proíbe a vogal oral no contexto $\mathrm{VN}\left(* \mathrm{~V}_{\text {ORAL }} \mathrm{N}\right)$ recebesse um peso diferenciado da restrição $* \mathrm{~V}_{\mathrm{NASAL}}$, também no espanhol (Hierarquia (gramática) da $\mathrm{LE}$ dos brasileiros $\rightarrow * \mathrm{~V}_{\text {NASAL }}(100.294) \mathrm{e} * \mathrm{~V}_{\text {ORAL }} \mathrm{N}(99.644)$; Hierarquia (gramática) dos uruguaios $\rightarrow * \mathrm{~V}_{\mathrm{NASAL}}(101.024) \mathrm{e} * \mathrm{~V}_{\mathrm{ORAL}} \mathrm{N}(100.737)$ ). Assim, no BiPhon, o melhor desempenho dos brasileiros na percepção da vogal nasalizada do espanhol, em comparação com os uruguaios, pode ser interpretado pelos valores centrais das restrições, que vão permitir maior ou menor movimentação na hierarquia. A Restrição de Estrutura violada pelos outputs com vogal nasal $\left(* \mathrm{~V}_{\mathrm{NASAL}}\right)$, na gramática 
da LE dos brasileiros, recebeu um peso central cuja distância é menor em relação às demais restrições, em comparação à hierarquia (gramática) dos uruguaios, informando que os outputs variáveis ocorrem de forma mais frequente na percepção dos brasileiros aprendizes de espanhol.

Cumpre ressaltar o argumento do texto a favor da presença das formas alofônicas no nível fonológico de superfície, que ainda contém detalhes fonéticos. Tal pressuposto significa que a ausência de vogais nasais na gramática do espanhol estaria determinada no nível do reconhecimento, nível meramente fonológico (veja-se FIGURA 1).

A investigação também mostrou o caráter variável da percepção em brasileiros aprendizes de espanhol e em uruguaios, com maior tendência, pelos uruguaios, de perceber vogal oral mesmo quando o input ouvido está nasalizado. Esse fato pode ser somado às evidências da natureza fonológica da percepção linguística.

\section{Contribuição das autoras}

As autoras trabalharam de maneira conjunta em todas as seções que integraram este artigo, respondendo cada uma pelo percentual 33,33\%.

\section{Referências}

ALVES, U. K. Teoria da otimidade estocástica e algoritmo de aprendizagem gradual: princípios de funcionamento e tutorial para simulação computacional. ReVEL, [S.l.], v. 15, n. 28, p. 202-234, 2017.

BAILEY, A. A. Similar, yet Different: Acquisition of Brazilian Portuguese Nasal Vowels by Spanish-English Bilinguals. In: AMARO, J. C. et al. (org.). Selected Proceedings of the 16th Hispanic Linguistics Symposium. Somerville: Cascadilla Proceedings Project, 2013. p. 128-142.

BISOL, L. Estudos sobre nasalidade. In: ABAURRE, M. B. M.; RODRIGUES, A. C. S. (org.). Gramática do Português Falado: novos estudos descritivos. Campinas: Editora Unicamp, 2002. v. VIII, p. 501535.

BOERSMA, P. Prototypicality Judgments as Inverted Perception. In: FANSELOW, G.; FÉRY, C.; SCHLESEWSKY, M.; VOGEL, R. (org.). Gradience in Grammar. Oxford: Oxford University Press, 2006. p. 167184. DOI: https://doi.org/10.1093/acprof:oso/9780199274796.003.0009 
BOERSMA, P. Cue Constraints and their Interactions in Phonological Perception and Production. Rutgers Optimality Archive, Berlin, n. 944, p. 1-42, 2007.

BOERSMA, P. Modelling Phonological Category Learning. In: COHN, A. C.; FOUGERON, C.; HUFFMAN, M. K. (org.). Handbook of Laboratory Phonology. Oxford: Oxford University Press, 2010. p. 207218.

BOERSMA, P. A Programme for Bidirectional Phonology and Phonetics and their Acquisition and Evolution. In: BENZ, A; MATTAUSCH, J. (org.). Bidirectional Optimality Theory. Amsterdam: John Benjamins, 2011. p. 33-72. Doi: https://doi.org/10.1075/la.180.02boe

BOERSMA, P.; HAMANN, S. Introduction: Models of Phonology in Perception. In: de Gruyter, 2009. p. 1-24.

BOERSMA, P.; HAYES, B. Empirical Tests of the Gradual Learning Algorithm. Linguistic Inquiry, Cambridge, v. 32, n. 1, p.45-86, 2001. DOI: https://doi.org/10.1162/002438901554586

BOERSMA, P.; PATER, J. Convergence Properties of a Gradual Learning Algorithm for Harmonic Grammar. Amsterdam: University of Amsterdam; UMass Amherst, 2008.

BOERSMA, P.; WEENINK, D. Praat. Doing Phonetics by Computer (versão 5.3.84). 2013. Disponível em: http://www.fon.hum.uva.nl/praat/. Acesso em: 10 abr. 2017.

BRISOLARA, L. B.; MATZENAUER, C. L. B. A percepção da vogal /a/ do espanhol, em contextos nasais, por brasileiros. Gradus: Revista Brasileira de Fonologia de Laboratório, Curitiba, v. 3, n. 1, p. 42-63, 2018a. DOI: https://doi.org/10.5935/2079-312X.20190002

BRISOLARA, L. B.; MATZENAUER, C. L. B. A nasalidade vocálica em espanhol: um estudo de percepção. Revista da Anpoll, Florianópolis, v. 1, n. 45, p. 12-29, 2018b. DOI: https://doi.org/10.18309/anp.v1i45.1102 BRISOLARA, L. B.; MATZENAUER, C. L. B.; SEARA, I. C. A vogal /a/ do espanhol em contexto nasal - a produção de brasileiros. Linguística, Montevideo, v. 35, n. 1, p. 11-34, 2019. DOI: http://dx.doi. org/10.5935/2079-312x.20190002 
CAGLIARI, L. C. An Experimental Study of Nasality with Particular Reference to Brazilian Portuguese. 1977. 320f. Tese (Doutorado em Filosofia) - School of Linguistics and English Language, University of Edinburgh, Edinburgh, 1977.

CÂMARA Jr, J. M. Manual de expressão oral e escrita. Petrópolis: Vozes, 1977.

CROSSWHITE, K. Vowel Reduction in Optimality Theory. New York: Routledge, 2001.

DELATTRE, P. Les Attributs Acoustiques de la nasalité vocalique et consonantique. Studia Linguistica, Reino Unido, v. 8, n. 2, p. 103-109, 1954. DOI: https://doi.org/10.1111/j.1467-9582.1954.tb00507.x

ESCUDERO, P. Linguistic Perception and Second Language Acquisition: Explaining the Attainment of Optimal Phonological Categorization. 2005. 348f. Tese (Doutorado em Linguística) - Utrecht University, Utrecht, Holanda, 2005.

GOUSKOVA, M. Optimality Theory in Phonology. In: BERND H.; NARROG, H. (org.). The Oxford Handbook of Linguistic Analysis. Oxford: Oxford University Press, 2009. p. 531-553. DOI: https://doi. org/10.1093/oxfordhb/9780199544004.013.0021

HARO, A. H. La percepción de la nasalidad en las vocales españolas. Vida Hispánica, Wollongong, v 44, p. 12-15, 2011.

HUALDE, J. I.; COLINA, S. Los Sonidos del Español. Cambridge: Cambridge University Press, 2014. DOI: https://doi.org/10.1017/ CBO9780511719943

KAGER, R. Optimality Theory. Cambridge: Cambridge University Press, 1999. DOI: https://doi.org/10.1017/CBO9780511812408

LINDBLOM, B. Phonetic Universals in Vowel Systems. In: OHALA, J. J.; JAEGER, J. J. (org.). Experimental Phonology. Orlando: Academic Press, 1986. p. 13-44.

NAVARRO TOMÁS, T. Manual de pronunciación española. Madrid: Consejo Superior de Investigaciones Científicas, 1918[2004]. 
PASCA, M. A. Aspectos da aquisição da vogal oral /a/ em língua espanhola por estudantes de língua portuguesa: a questão da percepção. 2003. 117f. Dissertação (Mestrado em Letras) - Instituto de Letras, Universidade Federal do Rio Grande do Sul, 2003.

QUILIS, A. Tratado de fonología y fonética españolas. Madrid: Editorial Gredos, 1999.

RAUBER, A.; RATO, A.; SANTOS, G.; KLUGE, D.; FIGUEIREDO, M. TP - Testes de Percepção / Tarefas de Treinamento Perceptual. 2012. Disponível em: http://www.worken.com.br/tp/tp_instala.html. Acesso em: 19 set. 2016.

RODRIGUES-ALVES, M. S. P. A nasalidade vocálica em português e em espanhol. 2014. 157f. Tese (Doutorado em Linguística e Língua Portuguesa) - Faculdade de Ciências e Letras, Universidade Estadual Paulista Júlio de Mesquita Filho, Araraquara, 2014.

SANTOS, G. B. Análise fonético-acústica das vogais orais e nasais do português: Brasil e Portugal. 2013. 198f. Tese (Doutorado em Linguística) - Faculdade de Letras, Universidade Federal de Goiás, Goiânia, 2013.

SEARA, I. C. Estudo acústico-perceptual da nasalidade das vogais do Português Brasileiro. 2000. 271f. Tese (Doutorado em Linguística) Centro de Comunicação e Expressão, Universidade Federal de Santa Catarina, Florianópolis, 2000.

SOUSA, E. M. G. Para a caracterização fonético-acústica da nasalidade no português do Brasil. 1994. 170f. Dissertação (Mestrado em Linguística) - Instituto de Estudos da Linguagem, Universidade Estadual de Campinas, Campinas, 1994.

SOUZA, L. C. da S. Análise acústica das vogais nasais e nasalizadas do português do Brasil e suas implicações fonético-fonológicas. 2013. 121f. Dissertação (Mestrado em Linguística) - Programa de Pós-Graduação em Linguística, Universidade Estadual do Sudoeste da Bahia, Vitória da Conquista, 2013.

VAQUERO DE RAMÍREZ, M. El español de América I: pronunciación. 3. ed. Madrid: Arco/Libros, 2003. 